E ISSN: 2622-223X

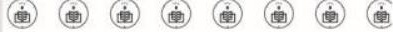

P ISSN: 2598-7607

Vol. II No. 01 (Maret - September) 2017

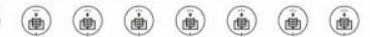

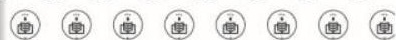

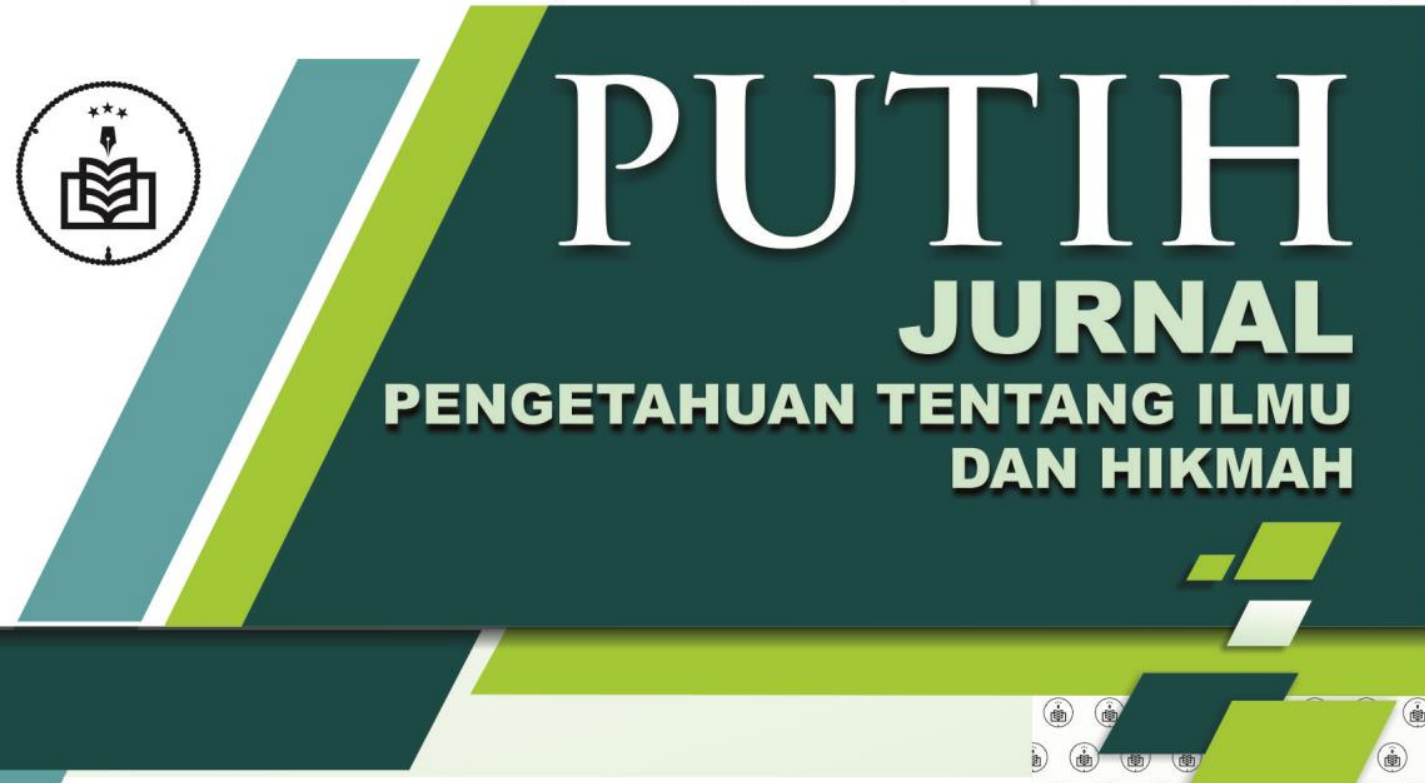

\section{HAKIKAT DOA}

Muhammad Husein Basofi 1-22

- MANAQIB SYEIKH ABDUL QADIR SEBAGAI MEDIA SULUK Durrotun Hasanah 23-42

- RELASI ANTARA AKAL DENGAN HATI PERSPEKTIF KH. ACHMAD ASRORI AL-ISHAQY Irwanto 43-64

- RELEVANSI AJARAN BUDHA DAN TASAWUF Mohammad Arista 65-100

- TERAPI SPIRITUAL MELALUI TAZKIYAH AL-QALB PERSPEKTIF ULAMA SHUFIYYAH

Anas Fajriansyah 101-122 (19i) (1) (19)

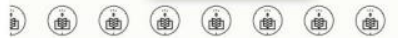

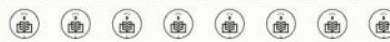

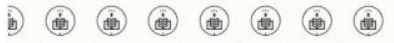

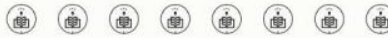

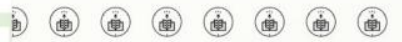

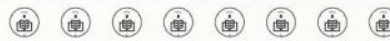

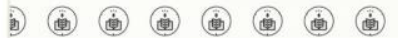

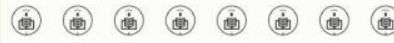
ib) (iii) (iii) (ii) (ii) (iii) (iii) (iit)

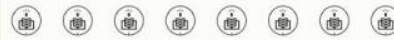

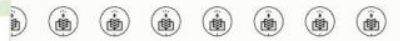

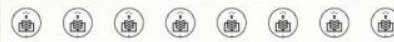

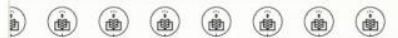

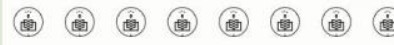

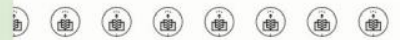

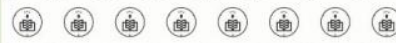

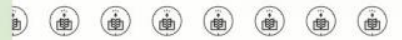

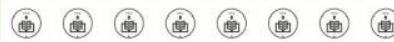
diterbitkan :

MA'HAD ALY

PONDOK PESANTREN ASSALAFI AL FITHRAH Surabaya 2017

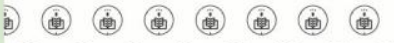

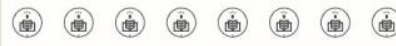
ib) (ii) (ii) (ii) (ii) (ii) (ii) (iii)

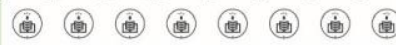
ib) (ii) (iii) (ii) (ii) (ii) (ii) (ii)

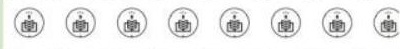

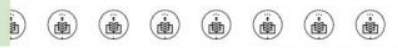




\section{REDAKTUR PUTIH \\ JURNAL PENGETAHUAN TENTANG ILMU DAN HIKMAH}

Ijin terbit

SK. Mudir Ma'had Aly No. 18/MAy-PAF/II/2017/SK

PENGARAH

Muhammad Musyafa'

Abdur Rosyid

Ahmad Syathori

Fathur Rozi

PIMPINAN REDAKSI

Fathul Haris

DEWAN EDITOR

Achmad Imam Bashori

ANGGOTA

Mustaqim

Samsul Arifin

Abdul Hadi

Alamat Penyunting dan Surat Menyurat :

Jl. Kedinding Lor 99 Surabaya

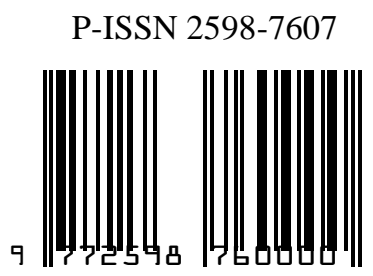

E-ISSN: 2622-223X

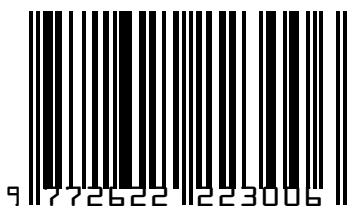

diterbitkan

MA'HAD ALY

PONDOK PESANTREN ASSALAFI AL FITHRAH

Surabaya 


\section{DAFTAR ISI}

DAFTAR ISI

— PEDOMAN TRANSLITERASI

ם HAKIKAT DOA

Muhammad Husein Basofi 1-22

— MANAQIB SYEIKH ABDUL QADIR SEBAGAI MEDIA SULUK

Durrotun Hasanah 23-42

RELASI ANTARA AKAL DENGAN HATI PERSPEKTIF KH. ACHMAD ASRORI AL-ISHAQY

Irwanto 43-64

- RELEVANSI AJARAN BUDHA DAN TASAWUF Mohammad Arista 65-100

TERAPI SPIRITUAL MELALUI TAZKIYAH AL-QALB PERSPEKTIF ULAMA SHUFIYYAH

Anas Fajriansyah 101-122 


\section{PEDOMAN TRANSLITERASI}

Berikut ini adalah skema transliterasi Arab-Indonesia yang ditetapkan dalam penulisan jurnal ini:

\begin{tabular}{|c|c|c|c|c|}
\hline $\mathrm{NO}$ & ARAB & INDONESIA & ARAB & INDONESIA \\
\hline 1 & 1 & 6 & b & t\} \\
\hline 2 & ب & B & ظ & $\mathrm{Z}\{$ \\
\hline 3 & ت & $\mathrm{T}$ & $\varepsilon$ & 6 \\
\hline 4 & ث & $\mathrm{Th}$ & $\dot{\varepsilon}$ & gh \\
\hline 5 & ج & $\mathrm{J}$ & ف & $\mathrm{F}$ \\
\hline 6 & $\tau$ & $\mathrm{h}\{$ & ق & Q \\
\hline 7 & $\dot{\tau}$ & $\mathrm{Kh}$ & 5) & $\mathrm{K}$ \\
\hline 8 & د & D & J & $\mathrm{L}$ \\
\hline 9 & j & $\mathrm{Dh}$ & r & $\mathrm{M}$ \\
\hline 10 & $\jmath$ & $\mathrm{R}$ & ن & $\mathrm{N}$ \\
\hline 11 & j & $\mathrm{Z}$ & 9 & W \\
\hline 12 & س - ل س & $S$ & a & $\mathrm{H}$ \\
\hline 13 & ش & $\mathrm{Sh}$ & $s$ & , \\
\hline 14 & ص & $s\{$ & ي & $\mathrm{y}$ \\
\hline 15 & ض & $d\{$ & & \\
\hline
\end{tabular}

Untuk menunjukkan bunyi hidup panjang (madd) dengan cara menuliskan coretan horizontal di atas huruf a, i>dan $u>($ ) $116)$. 


\title{
MANAQIB SYEIKH ABDUL QADIR SEBAGAI MEDIA SULUK
}

\author{
Durrotun Hasanah \\ Email: Durrotun Hasanah@gmail.com
}

STAI Al Fithrah Surabaya

\begin{abstract}
ABSTRAK
Salah satu program religius untuk mencapai sebuah suluk yakni dengan adanya majelis manaqiban yang mana majelis tersebut salah satu aktivitas jama'ah Al-Khidmah. Dan dalam majeis manaqiban tersebut ada beberapa isinya seperti tawassul yang ditujukan kepada Syeikh Abdul Qadir al-Jailani, kemudian dilanjutkan dengan Istighosah bersama, dan dilanjutkan dengan pembacaan manaqib yang di lengkapi dengan nasyid-nasyid juga dilengkapi dengan bacaan Maulidur Rasul.Dan motivasi dari adanya majelis ini yakni untuk menyambung silaturruhiyah kepada Guru, dan untuk mendekatkan diri kepada Allah.dengan adanya majelis ini seseorang yang ingin mencapai sebuah suluk sangat tepat sekali untuk mengikutinya. Karena setelah mengikuti majelis tersebut jiwa ini akan merasakan ketenangan. adapun persoalan ini termasuk persoalan yang bersifat perilaku manusia, oleh karena itu, untuk mengungkap persolan tersebut secra menyeluruh dan mendalam, maka dalam penelitian ini digunakan metode kualitatif. Kenapa penulis memilih metode yang kualitatif?, karena mnurut penulis metode ini lebih dapat beradaptasi dengan keadaan lingkungan.
\end{abstract}

Kata Kunci :Manaqib,Syeikh Abdul Qadir, Sebagai, Media, Suluk. 


\section{PENDAHULUAN}

Di kalangan para pengikut tarekat jaman sekarang ini, terkadang banyak seseorang yang tidak mengerti apa tarekat itu, apalagi ajaranajarannya. mereka hanya ikut-ikutan yang menyebabkan mereka tidak mengerti jauh apa sebenarnya tarekatitu, seperti halnya jama'ah tarekatAl-Qodiriyah Wa-Al-Naqsabandiyah Al-Ustmaniyah yang telah didirikan oleh Assyeikh KH.Muhammad ustman al-Ishaqy, yang mana ketika bertepatan pada tanggal 17 Ramadhan 1398 H/21 Agustus1978 M, Kh. Muhammad Ustman al- Ishaqy menalkin guru mursyid baru yang tak lain adalahputra dari pada beliau sendiri yakniKH.Achmad Asrori alIshaqy, yang mana di dalam ajarannya ituterdapat beberapa amalanamalan yang salah satunya tentang perjalanan hidupnya Syaikh Abdul Qodir Al-jailani ra, yang tak asing lagi mereka sebut dengan manaqiban.

Mungkin manaqib ini sudah bisa di bilang taka asing lagi bagi kalangan para tarekatAl-Qodiriyah Wa-Al-Naqsabandiyah AlUstmaniyah, dan salah satunya yang saya ketahui itu jamaa'ah alkhidmah, dan mereka sudah terbiasa mengikuti acara manaqiban tersebut, dan manaqibanitu juga bisa mengantarkan seseorang untuk bersuluk. akan tetapi yang menjadi kendala bagi para jamaa'ah ini bagaimana cara kita untuk menghayati makna dalam manaqib itu, dan mereka tidak mengerti maksud dari isi manaqib tersebut, sehingga di dalam hati mereka hanyalah sebuah ke hampaan belaka, yang mana sebuah robitohnya itu tidak sekuat para ahlu sufi. Seperti halnya yang saya ketahui manaqiban sering kali di lakukan satu bulan satu kali di Pondok Pesantren Assalafi Al-fithrah Surabaya, yang mana dengan adanya manaqib tersebut adalah salah satu cara untuk memperkuat tali ruhiyah para murid kepada mursyidnya (guru pemimbing ruhani). dan di dalam manaqib juga terdapat bentuk-bentuk nilai sufisme yang tanpa sadar tidak kita ketahui, di dalam manaqibantersebut di awali dengan bacaan tawassul yang di tujukan kepada para arwah-arwah guru-guru kita yang terdahulu dan untuk para sesepuh kita, orang tua kita dan setelahnya di lanjutkan dengan bacaan manaqibitu sendiri.

Manqiban inilah yang sangat cocok bagi para pemuda-pemudi jaman sekarang, yang mana mereka haus akan ketenangan jiwa mereka, karena dengan adanya manqib mereka bisa mengerti perjalanan tokoh 
sufi dari pendiri tarekatAl-Qodiriyah Wa-Al- Naqsabandiyah yang penuh dengan perjuangan dan lika-liku kehidupan. Ketika kita mengikutu acara mabaqiban secara istiqomah,mungkin sedikit demi sedikit kita akan faham apa isi dari manaqib itu, dan dengan ke fahaman kita dari isi manaqib inilah yang akan mengantarkan kita untuk bersuluk kepada sang maha pencipta langit dan bumi ini karena di era modern ini kita sebagai hamba seakan lupa kepada penciptanya. Penulis mengangkat judul manaqib sebagai media suluk ini agar bisa membumikan manaqib sehingga manaqib tidak hanya dikenal dikalangan santri dan alim ulama' saja tetapi juga bisa menjadi media atau perantara suluk bagi orang-orang awam dan masyarakat sekitar melalui majelis-majelis yang terselenggara.

Metodelogi penelitian yakni usaha seseorang yang dilakukan secara sistematis mengikuti aturan-aturan untuk menjawab suatu permasalahan yang hendak diteliti ${ }^{44}$ Jenis penelitian yang digunakan dalam jurnal ini adalah penelitian deskriptif kualitatif, yaitu peneliti berusaha menggambarkan kegiatan penelitian yang dilakukan pada objek tertentu secara jelas dan sistematis, Dan memprediksi terhadap suatu gejala yang berlaku atas dasar data yang diperoleh di lapangan. ${ }^{45}$ Jenis penelitian ini dapat mendeskripsikan fenomena atau aktifitas dari masyarakat, santri, atau jama'ah Pondok Pesantren Al-fithrah yang menjadi murid dari beliau KH.Achmad Asrori al-Ishaqy.

\section{BIOGRAFI SYEKH ABDUL QODIR AL-JAILANI}

Syekh Abdul Qodir al-Jailani yang nama lengkapnya adalah Abu Muhammad Abdul Qodir Jilani bin Abi Sholih Janki Dausat bin Abdillah bin Yahya bin Muhammad bin Daud bin Musa al-Tsani bin Abdillah alTsani bin Musa al-Jun bin abdillah al-Mahdi bin Hasan al-Mutsanna bin Hasan bin Ali bin Abi Tholib, adalah seorang guru sufi yang sempurna dan waspada serta arif, yang telah sampai pada cita-citanya, mempunyai kedudukan tinggi lagi mulia, pendirian yang kuat, dan ketetapan yang mantab, berbudi pekerti yang luhur dan kesempurnaan yang megah, dan

${ }^{44}$ Sukardi, Metodelogi Penelitian Pendidikan Kompetensi dan Prakteknya, (Jakarta: PT. Bumi Aksara, 2007), 19.

${ }^{45}$ Zainur Rofiq al-Shadiqi, Biografi Syekh Abdul Qadir al-Jilani (Jakarta: Zaman, 2011), 16 
juga seorang wali yang dekat dengan Allah SWT. Syekh Abdul Qodir alJailani adalah seorang yang mempunyai hubungan darah atau garis keturunan langsung bersambung sampai Rasulullah.Ia di lahirkan pada hari senin saat terbitnya fajar pada tanggal 1 Ramadhan $470 \mathrm{H}$ atau 1077 M di desa Jailan (bisa juga di sebut Jilan, Kailan, atau al-Jil). ${ }^{46}$ Nama desa itu kemudian di nisbatkan kepada Namanya yakni al-Jailani ataupun alJilani. Letak desa ini berada di kota terpencil yakni Tabaristan yang kini masuk wilayah Iran. Sedangkan untuk tahun kelahiran beliau yakni tahun $470 \mathrm{H}$. ini berdasarkan ucapan beliau kepada putranya (Abdul Razaq) bahwa beliau berusia 18 tahun ketika tiba di Baghdad, bertepatan dengan wafatnya ulama'terkemuka yakni al-Tamimi pada tahun $488 \mathrm{H}$.

Keistimewaan Syekh Abdul Qodir al-Jailani Nampak sejak beliau baru lahir, tepatnya pada tanggal 1 Ramadhan. Hal ini di karenakan sejak masih bayi Ia ikut puasa dengan tidak menetek kepada ibunya ketika siang hari. In berdasarkan penuturan Sayyidah Fatimah (ibunda Syekh Abdul Qodir al-Jailani). Dalam kisah ini sang ibu menuturkan "semenjak aku melahirkan anakku, ia tidak pernah menetek di siang hari pada bulan Ramadhan." Inilah salah satu karomah dari pada beliau. Syekh Abdul Qodir al-Jailani bukanlah sosok yang tidak mudah putus asa ataupun selalu berpangkutangan.Namun beliau merupakan sosok yang mempunyai semangat belajar dan rasa keingintahuan yang mengebugebu.Akhirnya, beliau mempunyai tekad yang bulat untuk memenuhi segala keinginannya tersebut.Hal ini terjadi ketika beliau mengetahui bahwasanya menuntut ilmu tu wajib hukumnya. Maka beliau memutuskan untuk menuntut ilmu di Baghdad pada tahun $488 \mathrm{H}$. dan usia beliau ketika itu sekitar 18 tahun. ${ }^{47}$ Syeikh Abdul Qadir wafat pada tanggal 11 Rabi'ul Akhir tahun $561 \mathrm{H}$. atau 1168 M. dalam usia 91 tahun dan beliau dimakamkan di Bab al-Azaj, Baghdad. ${ }^{48}$

\footnotetext{
${ }^{46}$ Terjemahan kitab manaqib BAB II

${ }^{47}$ Ibid, 43.

48 Syekh Abdul Qadir al-Jilani, Jangan Abaikan Syari'at: Adab-Adab Perjalanan Spiritual, terj. Tatang Wahyudin, (Bandung: Pustka Hidayah, 2007), 45.
} 


\section{PENGERTIAN MANAQIB}

Manaqib menurut bahasa adalah kisah kekekramatan para wali, sedangkan menurut istilah, manaqib adalah cerita-cerita mengenai kekeramatan para wali yang biasanya dapat didengar pada juru kunci makam, pada kekeluarga dan muridnya, atau di baca dalam sejarahsejarah hidupnya. ${ }^{49}$ Manaqib secara leksikal al-manaqib berarti kebaikan sifat dan sesuatu yang mengandung berkah.Dalam dunia tarekat, manaqib adalah catatan riwayat hidup Syekh tarekat yang memaparkan kisah ajaib dan hahiografis (sanjungan) dengan menyertakan ikhtisar hikayat, legenda, kekeramatan, dan nasehatnya.Semuanya itu di tulis oleh pengikut tarekat yang di rangkum dari cerita para murid, orang dekat, keluarga, dan sahabatnya.

Yang di maksud dengan manaqib secara istilah adalah membaca kisah tentang orang-orang soleh, seperti kisah Nabi atau auliya' (para kekasih Allah).Dalam tradisinya, kisah-kisah tersebut di tulis dengan menggunakan bahasa yang sangat indah dengan susunan kalimatnya yang benar-benar indah. Untuk lebih jelasnya lagi manaqib adalah sesuatu yang di ketahui dan di kenal pada diri seorang berupa prilaku dan perbuatan yang terpuji di sisi Allah SWT, sifat-sifat yang manis lagi menarik, pembawaan dan etika yang baik lagi indah, suci lagi luhur, kesempurnaan-kesempurnaan yang tinggi lagi agung, serta karomahkaromah yang agung di sisi Allah SWT. ${ }^{50}$ Manaqib ini adalah sebuah cerita atau sejarah kehidupan seorang wali yang harus di ceritakan kepada orang-orang agar mereka berfikir bahwasanya kisah hidup seorang wali itu seperti ini. Seperti halnya firman Allah yang berbunyi:

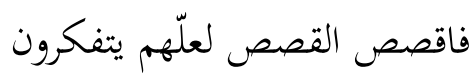

"Maka ceritakanlah (kepada mereka) kisah-kisah itu agar mereka berfikir". ${ }^{51}$ (QS. Al A'raf : 176).

\footnotetext{
${ }^{49}$ Abu Bakar Aceh, Pengantar Sejarah Sufi dan Tasawuf (Solo: Romadloni, 1990),355.

${ }^{50}$ Achmad Asrori al-Ishaqy, Apakah Manaqib itu?, (Surabaya: Al-Wava, 2010), 9.

${ }^{51}$ Ibid, 13.
} 
Jadi bisa ditarik kesimpulan dari kedua devinisi manaqib yang berbeda diatas tersebut bahwasanya manaqib ini bisa di jadikan sebagai uswah dan sebuah ilmu saja. Jika menurut KH.Achmad asrori al-Ishaqi manaqib adalah sebuah uswah bagi jama'ah.Yang mana mereka dapat mencontoh perilaku-perilaku baik dari Syaikh abdul Qadir al-Jailani. Dan jika menurut Abu Bakar Aceh manaqib itu sebuah pengetahuan atau cerita tentang para kekasih Allah, orang-orang shaleh dan para Wali Allah.

\section{MAJELIS MANAQIBAN}

Majelis manaqiban mungkin tak asing lagi bagi kalangan jama'ah.dan isi dari pada majelis manaqiban ini yaitu tawassul terlebih dahulu, yang ditujukan kepada guru, para sesepuh, orang tua, dan orangorang mukmin, kemudian istighosah Dan setelah itu di lanjutkan dengan pembacaanmanaqib sultonil auliya' sayyidina syekh Abdul Qadir Aljailani, kemudian dilanjutkan dengan beberapa bacaan nasyit juga dzikiran. Adapun setelah pembacaan manaqib telah usai maka di lanjutkan dengan pembacaan Maulidur Rasul SAW.

Majelis manqiban (selnajutnya disebut manaqiban), adalah salah satu dari berbagai macam ritual religious yang diadakan oleh "Jama'ah Al Khidmah" dibawah bimbingan Syaikh Ahmad Asrori al-Ishaqy ra.Manaqiban juga merupakan salah satu dari beberapa macam media syi'ar Pondok Pesantren Assalafi Al Fithrah. Dan penulis mengutip dari jurnal putih yang diterbitkan oleh Ma'had Aly bahwasanya didalamnya itu terdapat tulisan Ustadz Nasiruddin yang didapatkan melalui Bapak H. Ainul Huri bahwasanya manaqiban itu merupakan ujung tombak Syi'ar yang dibawa oleh KH. Ahmad Asrori al-Ishaqy ra.Dan dalam salah satu ayat Al-qur'an Allah berfirman:

$$
\text { وذكلّ نقصّ عليك من أنباء الرّسل ما نثبّت به فؤادك وجاءك في هذه الحقّ وموعظة }
$$


"Semua kisah dari para Rasul kami ceritakan kepadamu, ialah kisah-kisah yang dengannya kami teguhkan hatimu, dan telah datang kepadamu kebenaran serta pengajaran dan peringatan bagi orang-orang yang beriman". QS. Hud: $120 .{ }^{52}$

Majelis manaqiban yang telah diuraikandiatas yakni salah satu majelis manaqiban yang di ketahui oleh sang penulis sendiri. yang mana dalam majelis ini sudah ada tim pembaca, yang mempunyai tanggung jawab akan bacaannya. jadi tidak hanya sembarang orang yang membaca tetapi dari tim inilah yang akan membacanya. Tim pembaca ini pulalah yang akan "membawa" jama'ah untuk dapat merasakan esensi dari majelis.dengan penghyatan makna bacaan dan kefasihan bacaan yang benar, akan memperoleh seperti apa yang telah di sebut oleh Khatib Ahmad Santhut sebagai pengaruh baik dalam pendidikan spiritual. Dan semua nasyit (termasuk suara dan lagu) yang dihiasi dengan pesan akan mempertautkan hamba dengan tuhannya. ${ }^{53}$

Adapun isi dalam majelis manaqiban jika dalam Pondok Pesanren Assalafi al-Fithrah antara lain:

1. Pembacaan doa kepada ahli kubur

2. Lalu dilanjutkan membaca yasin dan manaqib 1 sampai 7 yang berisi tentang pengertian manaqib, sifat-sifat dan pembawaan dari wali-wali Allah, tipu dayailmu, bid'ah (pembaruan), Ahlussunnah wal jama'ah, berisi doa'

3. Lalu dilanjut lagi pembacaan ibadallah dan la ilaaha illallah

4. Pembacaan sholawat lalu di tutup dengan doa. Dipimpin langsung oleh KH. Achmad Asrori Al Ishaqi dan para Muhibbin Muhibbat dan acara dilaksanakan oleh oraganisasi Al-Khidmah.

52 Sekelompok tim, Putih Jurnal Pengetahuan Tentang Ilmu dan Hikmah, (Surabaya: Ma'had Aly, 2018), 47-48.

${ }^{53}$ Khatib Ahmad Santhut, Daur al-Bait fi tarbiyah al-Tifl al-Muslim, terj. Ibnu Burdah, Menumbuhkan Sikap Sosial, Moral dan Spiritual anak dalam keluarga Muslim, (Yokyakarta: Mitra Pustaka, 1998),216. 
Kegiatan manaqib dilakukan karena sudah terjadwal dan tersusun rapi dalam pelaksanaannya. Manaqiban, adalah kegiatan membaca kitab manaqib secara berjamaah dan dilagukan seperti membaca sya'ir. Isi kitab manaqib tersebut meliputi: Silsilah nasab syekh Abdul Qadir Jilani, sejarah hidupnya, akhlak karamah-karamahnya, selain itu juga adanya doa-doa bersajak yang bermuatan pujian dan tawassul melalui dirinya. Kegiatan ini dilakukan setiap malam ahad awal (pondok pesantren alfithrah).Kegiatan ini dilakukan untuk mengenang wafatnya pendiri Tarikat Qodiriyah yakni Syekh Abdul Qodir Al Jilani yang wafat tanggal 11 Rabi'ul Akhir $561 \mathrm{H}^{5}$

Adapun tradisi membaca manaqib tersebut biasanya, di lakuakan oleh masyarakat yang berfaham teologi Ahlussunnah wal Jama'ah, khususnya kaum Nahdliyin (NU) dan biasanya di baca ketika ada hajatan-hajatan tertentu atau khusus, seperti halnya majelis tahlil, lamaran akad nikah, walimat al-'arusy, walimat al-hamli (7 bulan masa kehamilan), walimat al-tazmiyah (pemberian nama dan potong rambut), haul (satu tahun meninggalnya seseorang), dan juga termasuk miladiyah (ulang tahun kelahiran) seseorang atau bahkan sebuah intuisi (pondok pesantren).

\section{TUJUAN DARI MAJELIS MANAQIBAN}

Tujuan melaksanakan manaqib adalah untuk meningkatkan amal ibadah kepada Alllah swt.dengan cara mencintai dan memuliakan para orang sholeh (Auliya Allah) dengan maksud untuk meneladani atau mencontoh amal sholehnya. maka kelak diakhitat akan berkumpul bersamanya, sesuai dengan sabda Nabi :

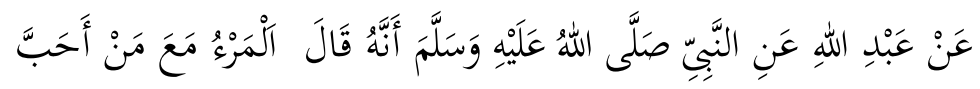

Dari Abdillah dari nabi saw, bahwasanya beliau bersabda:

Seseorang itu bersama orang yang dicintai. (H . R. Bukhari no. 6168)

\footnotetext{
${ }^{54}$ Bruinessen Martin Van, Tarekat Naqsabandiyah di Indoneseia, (Bandung: Mizan, 1998), 112.
} 
Mengutip dari rekaman serasehan beliau Nyai Selvi tentang manaqib bahwasanya beliau mengatakan manaqib itu sesuatu yang sangat yang bagus bagi orang-orang yang ingin mendekatkan diri pada Allah. ${ }^{55}$ Karena manaqib adalah sebuah cerita mengenai karomahnya para wali ataupun Nabi dan para Sahabatnya maka banyak sekali di dalam alqur'an yang menjelaskan mengenai manaqibnya Maryam, manaqib Dzulqamain, manaqib ashabul Kahfi dan lain-lain. Demikian pula setelah Nabi wafat ada manaqib Abu Bakar, manaqib Umar bin Khattab, manaqib Ali bin Abi Thalib, manaqib Hamzah, manaqib Abi Sa'id, manaqib at-Tijani, dan salah satunya manaqib dari Syekh Abdul Qadiral-Jailani yang mana manaqibnya beliaulah yang penulis angkat sebagai sebuah jurnal, yang mana dari manaqib-manaqib yang telah di sebutkan di atas itu sedikit meyenggol atas firman Allah yang berbunyi:

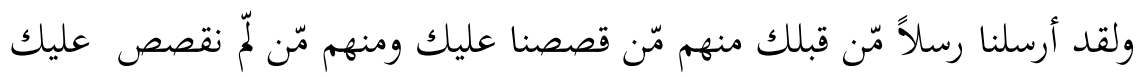

dan sesungguhnya telah kami utus beberapa orang Rasul sebelum kamu, di antara mereka ada yang kami critakan kepadamu dan di antara mereka ada (pula) yang tidak kami ceritakan kepadamu. ${ }^{56}$

Maka penulis sedikit mengutip dari ayat tersebut untuk memenuhi beberapa referensi dari sebuah jurnalanya adapun alasan kenapa penulis mengutip ayat tersebut karna menurut penulis ayat yang di atas tersebut sudah termasuk atau sedikit menjerumus pada sebuah jurnalnya yang mana penulis di sini lebih memilih untuk mengangkat manaqib dari Syekh Abdul Qadir al-jailani dikarenakan supaya beberapa orang yang mengikuti atau membaca sebuah manaqibnyaSyekh Abdul Qadir ini lebih mengerti maksud cerita perjalanannya beliau dan penulis mengharapkan semoga kecintannya kepada beliau lebih dalam lagi karena beliau termasuk salah satu wali Allah yang telah mendapat julukan Sultonil Auliya' yaitu pemimpinnya para wali Allah.

\footnotetext{
${ }^{55}$ Rekaman serasehan manaqib bersama beliau Nyai Selvi.

${ }^{56}$ QS. Al-Mukmin, ayat: 78.
} 
Sudah sangat jelas sekali bahwasanya dengan adanya manaqib ini bisa mengantarkan seseorang untuk bersuluk seperti halnya yang telah tercantum di dalam terjemahan kitab manaqib bab 1 yang mana di dalamnya telah di jelaskan bagaimana perjuangan-perjuangan yang telah beliau lakukan bagaimana kita bisa melewatkan bacaan manaqib ini? Sedangkan di dalamnya tersebut banyak cerita-cerita mengenai perjalanan hidup beliau, karomah-karomah yang ada pada diri beliau serta dalam kitab ini juga menceritakan kewafatannya beliau, yang mana ketika kita faham kita tak akan bisa mampu menahan cairan-cairan bening yang akan keluar dari kelopak mata kita, maka dari itulah sedikit demi sedikit manaqib ini akan mengantarkan kita untuk bersuluk kepadaNya. $^{57}$

Tujuan daripada penyelenggaraan aktivitas manaqib adalah untuk mencintai dan menghormati keluarga dan keturunan Nabi Saw, mencintai para orang sholeh, dan Auliya', mencari berkah dan syafa'at dari Syeikh Abdul qadir al-Jailani. ${ }^{58}$ Seperti halnya yang telah di terangkan ustadz rosid mengenai kitab manaqib beliau menerangkan bahwasanya Di dalam kitab manaqib juga sudah di jelaskan bahwasanya seseorang itu di suruh untuk mensucikan dirinya sendiri agar pantas ketika hendak menghadap Allah, maka dari itu Allah lebih banyak memberi sebuah penyakit itu pada seseorang yang sudah lanjut usia ketika kita melihat secara dhohirnya, karena jika di lihat pada dohirnya orang yang sudah lanjut usia itu yang akan menghadap kepada Allah (wafat), justru dari itulah kasih sayang Allah lebih melimpah buktinya Allah memberi sebuah penyakit supaya seseorang tersebut berdzikir kepada-Nya.

Inilah salah satu karomah beliau yang dicantumkan oleh penulis dan masih banyak lagi mengenai karomah-karomahnya beliau dan salah satu dari karomahnya beliau ialah: cerita yang mana pada tahun 537 H.dan bapak dari anak tersebut menceritakan sebuah kisah. Bapak anak perempuan: anak perempuanku seorang perawan berusia 16 tahun naik ke atas atap rumahku dan kemudian hilang. Akupun pergi menghadap

${ }^{57}$ Baidlowi Syamsuri, Penuntun Manaqib Syekh Abdul Qadir al-Jailani, (Surabaya: Apollo), 20.

${ }^{58}$ Sa'id, A Fuad, Hakekat Tarekat Naqsabandiyah, (Jakarta: Pustaka al-Husna, 1994), 68. 
Syaikh Abdul Qadir dan menceritakan hal tersebut. Dan Syaikh Abdul Qadir berkata:

Syaikh Abdul Qadir: "Pergilah ke pegunungan Al-Karh. Duduklah di puncak ke lima dan buatlah tanda lingkaran di sekitarmu sambil berkata, 'BismiLlaahiRrahmaanirRahiim, atas niat Syaikh Abdul Qadir. Nanti ketika hari mulai gelap akan banyak jin yang melewatimu. Mereka tidak akan dapat menyakitimu. Pada waktu sahur, raja raja mereka akan lewat beserta bala tentaranya dan mereka akan menanyakan maksud kedatanganmu. Saat itulah ceritakan kepada mereka perihal anakmu'.

akupun melaksanakan perintah tersebut. Ketika hari mulai gelap, geromblan jin dengan bentuk yang sangat menakutkan namun mereka tidak dapat menyakitiku atau menggangguku. Gerombolan demi gerombolan terus berlalu hingga waktu sahur datanglah raja mereka dengan mengendarai seekor kuda dan berdiri di luar lingkaran menghadap ke arahku. Sambil berkata:

Raja Jin: 'hai manusia apa keperluanmu’.

Bapak anak perempuan: "Syaikh Abdul Qadir mengutusku kepadamu". Jawabku. Begitu mendengar nama Syaikh Abdul Qadir maka raja jin tersebut turun dari kudanya mencium tanah dan duduk, begitu pula dengan para jin lain yang menyertainya. Kemudian ia berkata:

Raja Jin: 'apa yang terjadi pada dirimu?

Bapak anak perempuan: akupun menceritakan kepada mereka akan kisah puteriku yang hilang. Setelah mendengar penuturanku, dia berkata kepada para jin.

Raja Jin: 'Siapa yang melakukan ini'. Tidak ada satu jinpun yang mengakuinya. Lalu datanglah seorang jin bersama anakku. Sang raja berkata, 'ini adalah pembangkang dari negeri cina. 'apa 
yang mendorongmu berani melakukan hal ini di bawah atap sang qutb ?'. tanyanya kepada jin tersebut.

Jin tersebut berkata: 'perempuan tersebut menarik hatiku dan aku mencintainya'. Sang raja kemudian memerintahkan jin tersebut untuk dipenggal kepalanya dan menyerahkan anakku kembali. Dan aku berkata kepadanya:

Bapak anak perempuan: 'Aku belumpernah melihat jin dengan derajad tinggi sepertimu memenuhi perintah Syaikh Abdul Qadir Dia berkata:

Raja Jin: 'Benar, dari rumahnya beliau memandang kepada jin pembangkang yang pada waktu itu berada di dasar bumi.kewibawaannya membuat para pembangkang tersebut kembali ke tempat mereka. Sesungguhnya jika Allah mengangkat seorang Qutb maka Dia akan menjadikannya sebagai Qutb diantara jin dan manusia. $^{59}$

Salah satu dari karomahnya beliau juga yakni sebuah cerita yang mana Syeikh Abdul Qadir itu tidak suka mengagung-agungkan orang kaya:

Syekh Abdul Qadir al-Jilani mempunyai kepribadian tidak mau mengagung-agungkan orang kaya.Sering kali Khalifah bermaksud silaturrahim kepada beliau.Meskipun ketika itu awalnya beliau dalam keadaan duduk, pasti jika mengetahui ada Khalifah atau Raja hendak menuju rumahnya, seketika itu beliau juga langsung bergegas masuk ke kamar.Sementara setelah Khalifah duduk, baru beliau keluar dari kamar.Hal dilakukan hanya sekedar memuliakan perilaku ahli tasawuf yang tidak tertarik pada kedudukan dan

${ }^{59}$ Terjemahan Manaqib BAB VI 
harta.Dan sering juga beliau menolak pemberian Khalifah atau Raja. $^{60}$

Pernah suatu ketika Syeikh Abdul Qadir didatangi oleh seorang Raja (Abul Mudhaffar). Maksud dari kedatangan sang Raja adalah memberikan hadiah berupa 10 kantong uang kepada Syeikh AbdulQadir. Namun Syeikh Abdul Qadir tidak mau menerimanya meski sang Raja sudah merayunya hingga sedemikian rupa. Akhirnya, sang Raja meminta kepada Syeikh Abdul Qadir agar memberinya apel, padahal pada saat itu tidak musim apel. Syeikh Abdul Qadir pun kemudian mengangkat tangannya ke atas dan seketika itu juga ada 2 apel ditangannya.Lantas yang satu beliau berikan kepada Abul Mudhaffar, dan satunya lagi untuk dirinya. Dan anehnya ketika apel itu dipecah isinya tidak sama antara yang dipegang Syeikh Abdul Qadir dan Abul Mudhaffar. Apel yang dipegang Syeikh Abdul Qadir tampak putih dan masih segar, sedangkan apel yang ada ditangan Abul Mudhaffar berbau busuk dan banyak cacingnya. ${ }^{61}$ Maka sang Raja pun langsung mencium tangan Syeikh Abdul Qadir lalu meminta maaf kepadanya.

Maka dari cerita inilah bisa di tarik kesimpulan bahwa salah satu karomahnya Syaikh Abdul qadir yang telah mendapat julukan al- Qutb. Dan Syeikh Abdul Qadir tidak terlena akan kenikmatan dunia seperti halnya cerita mengenai sang Raja diatas.

Adapun seseorang yang ingin mencapai sebuah suluk maka harus melewati perantara-perantaranya terlebih dahulu atau harus mempunyai media supaya mencapai suluk.yang mana medianya itu seperti halnya majelis-majelis dzkir yang di dalamnya telah tersusun rapi mengenai urutan-urutannya seperti misalnya tawassul terlebih dahulu kemudian diiringi dengan bacaan-bacaan manaqib.

Jadi majelis-majelis dzikir itulah yang telah menjadi perantara atau media seseorang untuk mencapai suluk. Karena tanpa adanya majelis-

${ }^{60}$ Syekh Muhammad Yahya al-Tadafi, Mahkota Para Aulia: Syekh Abdul Qadir alJailani, (Surabaya: Cempaka, 2014),34.

${ }^{61}$ Ibid, 36. 
majelis itu maka seseorang yang ingin meraih suluk tidak akan dapat meraihnya karena salah satu media atau perantara pengantar suluk itu tidak lain dengan cara mengikuti majelis dzikir tersebut.

Begitupun ungkapan beliau Nyai Selvi mengatakan bahasanya menghadiri sebuah mejelis itu adalah salah satu cara untuk mendekatkan diri pada Allah, dan beliau juga mengutip dari sabdanya rasul yang berbunyi "sesungguhnya hati ini berat dan sesungguhnya penjernihannya adalah membaca Al-Qur'an, ingat mati, dan menghadiri majelis untuk berdzikir". Maka bisa ditarik kesimpulan bahwa sesuatu yang bisa menjernihkan hati itu salah satunya adalah dengan menghadiri sebuah majelis dan ketika hati kita jernih kita akan selalu merasa dekat dengan-Nya. ${ }^{62}$

Ketika kita mengikuti sebuah majelis maka di dalamnya itu banyak variasinya yang mana salah satunya mengenai berdzikir dan kata dzikir itu berasal dari bahasa arab(ذكر-يذكر-ذكرا) yang artinya menyebut atau mengingat. Jadi bisa di tarik kesimpulan bahwasanya mengikuti sebuah majelis tidak lain untuk mengingat Allah. ${ }^{63}$

Dzikir juga merupakan sarana untuk mengingat Allah dan lebih mendekatkan diri padaNya. Dan orang yang mempunyai kebiasaan berdzikir, maka dalam tidurnyapun ia akan selalu berdzikir dalam hati. Dzikir juga bisa digunakan sebagai obat bagi orang yang memiliki hati yang keras. ${ }^{64}$

Maka dapat kita pahami bahwa membaca manaqib Syaikh Abdul Qadir Jilani itu sangat baik. Karena akan menambah kecintaan kita kepada beliau, yang notebenenya adalah salah seorang wali Allah,

${ }^{62}$ Syeikh Abdul Qadir Jailani, pada halaqah Shufiyyah di madrasah An-Namurah, yang telah di terjemahkan oleh: KH. Habib Abdullah Zaky Al-Kaaf,Ajaran Tasawuf Syeikh Abdul qadir Al-Jailani, (Bandung: CV Pustaka Setia 2003), 149.

${ }^{63}$ M. Arifin Ilham dan Bebby Nasution, Hikmah Dzikir Berjama'ah, (Jakarta: Republika,2003),112.

${ }^{64}$ Mujahidin, Anding.Syekh Abdul Qadir Al-Jailani.(Jakarta: Zaman, 2011), 112. 
bahkan beliau disemati gelar sebagai sulthan al-awliya atau pemimpin para wali. Seperti halnya hadist yang diriwayatkan oleh H.R. BukhariMuslim yakni:

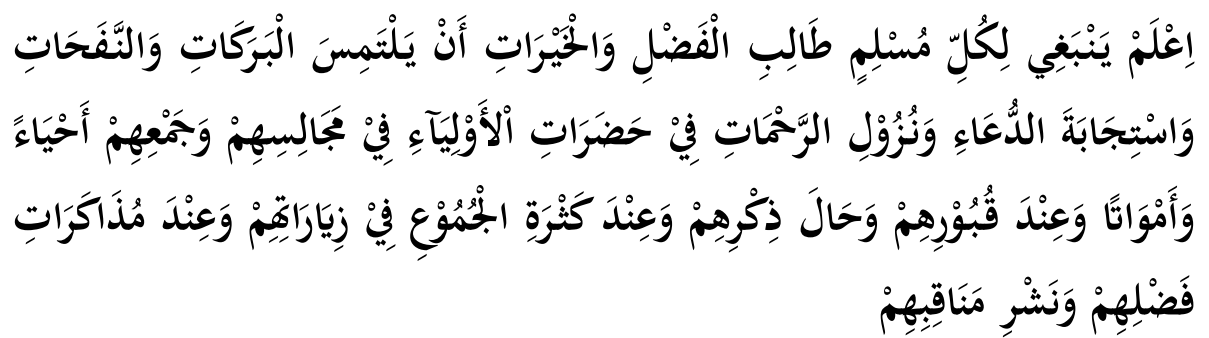

"Ketahuilah! Seyogyanya bagi setiap muslim yang mencari keutamaan dan kebaikan, agar ia mencari berkah dan anugrah, terkabulnya doa dan turunnya rahmat di depan para wali, di majelis-majelis dan kumpulan mereka, baik yang masih hidup ataupun sudah mati, di kuburan mereka, ketika mengingat mereka, dan ketika banyak orang berkumpul dalam berziarah kepada mereka, serta ketika mengingat keutamaan mereka, dan pembacaan riwayat hidup mereka". ${ }^{65}$

\section{EFEK SETELAH MENGIKUTI MAJELIS MANAQIBAN}

Disini penulis sedikit mewawancarai jama'ah yang biasanya ikut majelis manaqiban yang ada dipondok al-fithrah. Dan penulis ingin mengetahui apa efek ketika jma'ah ini selesai mengikuti acara majelis tersebut. Ketika selesai mengikuti acara majelis manaqib ini seperti beban yang ada pada diri saya ini seakan hilang dengan sendirinya karena dengan mendengarkan saja hati saya sudah begitu enak terasa tenang dan itu semua juga tergantung pada yang membacanya karena mereka yang membacanya itu yang akan membawa jama'ah seperti saya ini untuk meresapinya. Dan dari sinilah saya selalu ingin mengikuti acara majelis manaqib, jika memang ada seperti halnya yang ada dipondok al-fithrah

${ }^{65}$ Alawi al-Haddad, Misbah al-Anam Wa Jala' azh-Zhulam, (Istanbul: Maktabah alHaqiqah, 1992), 90 
yang dilakukan setiap satu bulan satu kali ini dan saya selalu ikut manaqib minggu awal tersebut jika memang saya tidak mempunyai halangan yang sangat mendesak. ${ }^{66}$

Jadi jama'ah ini juga sering membaca terjemahan kitab apa itu manaqib yang mana dalam terjemahan ini ada sabda Rasulullah yang berbunyi:

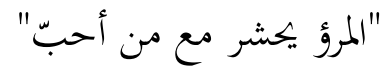

"Seseorang akan dikumpulkan beserta orang yang dicintai"

Dan dari sinilah jama'ah tersebut mendapat motivasi untuk selalu ikut acara majelis manaqib menurut jam'ah ini mungkin dari saya mencintai manaqib ini saya kelak akan dikumpulkan dengan orang yang sholeh. Salah seorang alumni pondok pesantren assalafi al-fithrah menjelaskan bahwa manfaat membaca kitab Manaqib ini adalah untuk mendapat berkah dari Allah melalui perantara syekh Abdul Qadir Jilani. Namun, secara umum diterimanya amalan manaqiban oleh para kiyai di Jawa khususnya, karena dalam kitab manaqib disebut-sebut nama para Nabi dan orang-orang saleh. Sedangkan jama'ah yang membaca kitab manaqib tersebut terdiri dari berbagai macam usia, mulai anak-anak, remaja, hingga dewasa. Sehingga dengan adanya kegiatan ini anak-anak maupun remaja bisa terhindar dari kegiatan-kegiatan yang kurang bermanfaat, seperti: main game, nonton TV bersenda gurau dan lainlain. ${ }^{67}$

Salah satu jamaah tarekat Qadiriyah wa Naqsabandiyah beliau merasakan jiwanya menjadi tenang setelah menjalankan amalanamalannya. Ini berarti sesuai dengan firman Allah bahwa orang-orang yang beriman dan hatinya tentram dengan mengingat Allah, hati akan menjadi tentram (Al Qur'an: 13, 28). Dengan demikian bacaan dzikir yang dibaca dengan sepenuh hati dan penghayatan yang sungguh sungguh akan dapat membersihkan hati dan jiwa dari segala macam

\footnotetext{
${ }^{66}$ Wawancara, Inung Sulistyorini, pada hari sabtu tanggal 23, Maret, 2019.

${ }^{67}$ Wawancara, Ummi Kulsum, pada tanggal, 11 Maret 2019.
} 
kotoran jiwa dan penyakit hati. ${ }^{68}$ Di samping itu, pembacaan manakib juga mempunyai banyak manfaat antara lain: untuk ketentraman hati dan memeberi semangat untuk selalu bersimpuh diharibaanNya. Dengan pembacaan manaqib secara rutin, diharapkan pembaca bisa menjadikan Syeikh Abdul Qadir sebagai suri tauladan yang baik. ${ }^{69}$

\section{MANAQIB SEBAGAI MEDIA SULUK}

Ketika seseorang ingin mencapai suluk maka harus ada perantaranya terlebih dahulu yakni dengan cara mengikuti majlis manaqiban seperti yang telah diuraikan terlebih dahulu yang nantinya akan membawa kita kepada-Nya di karenakan kita juga berkumpul bersama orang-orang yang sholeh. Manaqib dikatakan sebagai media suluk Karena dalam majelis manaqib ini kita di kumpulkan dengan para kekasih Allah dan dalam majelis ini kita juga berdoa' bersama-sama juga untuk menyambung tali slaturrahmi kita terhadap sesama muslim. Manaqib ini sebagai pengantar suluk bagi seorang salik yang ingin mendekatkan diri kepada Allah maka dari sini penulis ingin menjelaskan sedikit mengenai apa itu suluk. Suluk perjalanan ruhani seorang hamba dengan tujuan untuk mendekatkan diri, memohon ampunan, dan berkehendak mendapat ridho Allah SWT.Dengan melalui tahapantahapan penyucian jiwa yang diperaktekkan kedalam latihan-latihan ruhani secara istiqamah. Jadi dengan mengikuti majelis manaqiban makaseseorang tersebut akan sedikit demisedikit belajar untuk menyucikan jiwa dan mendekatkan diri pada Allah. ${ }^{70}$

\footnotetext{
${ }^{68}$ Wawancara, Muhammad Bahrowi, pada tanggal, 20 Maret 2019.

${ }^{69}$ Al-Nabawi, Abul Hasan, Syekh Abdul Qadir Jaelani, penerjemah Abu Asma. (Solo: CV, Ramadhani, 1985), 96.

70 Mahfudh Shalahuddin, Pengantar Psikologi Pendidikan, (Surabaya: PT. Bina Ilmu, 1990), 80 .
} 


\section{KESIMPULAN}

Atas uraian diatas tersebut maka permasalahan mengenai manaqib sebagai media suluk pada kalangan jama'ah manaqiban dapat disimpulkan bahwasanya:

1. Manaqib itu sebagai media suluk yang mana ketika jama'ah sering kali mengikuti majelis manaqiban karena dengan cara mengikuti majelis manaqiban maka sedikit demi sedikit akan menimbulkan rasa cinta pada jama'ah tersebut dan didalam majelis manaqibanpun tak lain jama'ah tawassul, membaca manaqib, membaca mauled dan berdoa' bersama. Maka diri sinilah dapat disimpulkan bahwasanya manaqib itu salah satu perantara untuk mencapai suluk.

2. Adapun manfaat dan tujuan daripada mengikuti majelis manaqiban ini sangat banyak sekali dan mannfaatnya yakni hati jamaa'ah terasa tentram dan tidak ada beban yang ada didalam hatinya, juga untuk menyambung tali silaturrahim kepada sesame muslim yang mana telah dijelaskan terlebih dahulu dipembahasan bahwasanya manfaat dan tujuannya itu sangat penting sekali. Dan demikian itu juga telah disebutkan dalam beberapa ayat dan hadist, juga peraktek ataupun efek dari mengikuti majelis manaqiban menurut jama'ah dan alumni Pondok Pesantren yang terdahulu.

3. Didalam majelis manaqiban itu juga dijelaskan mengenai biografi Syeikh Abdul Qadir dan beberapa karomahnya, juga menjelaskan apa arti dari manaqib itu sendiri. yang mana sudah dipaparkan terlebih dahulu oleh penulis mengenai arti dari manaqib perspektif $\mathrm{KH}$. Ahmad Asrori al-Ishaqy dan perspektif penulis buku yakni Abu Bakar Aceh. Dan hasilnya pun berbeda Karena menurut KH. Ahmad Asrori al-Ishaqy manaqib itu sebuah uswah bagi jama'ah. Yang mana mereka dapat mencontoh perilaku-perilaku baik dari Syaikh abdul Qadir al-Jailani.

Dan jika menurut Abu Bakar Aceh manaqib itu sebuah pengetahuan atau cerita tentang para kekasih Allah, orang-orang shaleh dan para Wali Allah. 


\section{DAFTAR PUSTAKA}

Aceh Abu Bakar. Pengantar Sejarah Sufi dan Tasawuf Solo: Romadloni, 1990.

Ishaqy (al). Asrori Achmad, Apakah Manaqib itu?, Surabaya: Al-Wava, 2010.

Alawi. al-Haddad, Misbah al-Anam Wa Jala' azh-Zhulam, Istanbul: Maktabah al-Haqiqah, 1992.

Nabawi (al). Abul Hasan. Syekh Abdul Qadir Jaelani, penerjemah Abu Asma. Solo: CV, Ramadhani, 1985.

Tadafi (al). Yahya Muhammad Syekh. Mahkota Para Aulia: Syekh Abdul Qadir al-Jailani, Surabaya: Cempaka, 2014.

Jilani (al). Abdul Qadir Syekh. Jangan Abaikan Syari'at: Adab-Adab Perjalanan Spiritual, terj. Tatang Wahyudin, Bandung: Pustka Hidayah, 2007.

Anding Mujahidin. Syekh Abdul Qadir Al-Jailani. Jakarta: Zaman, 2011.

Shadiqi (al). Rofiq Zainur.Biografi Syekh Abdul Qadir al-Jilani Jakarta: Zaman, 2011.

Bruinessen Martin Van.Tarekat Naqsabandiyah di Indoneseia, Bandung: Mizan, 1998.

Ilham Arifin M. dan Nasution Bebby.Hikmah Dzikir Berjama'ah, Jakarta: Republika,2003.

Fuad A Sa'id. Hakekat Tarekat Naqsabandiyah, (Jakarta: Pustaka alHusna, 1994), 68. 
Jailani Abdul Qadir Syeikh. padahalaqah Shufiyyah di madrasah AnNamurah, yang telah di terjemahkan oleh: Al-Kaaf Zaky Abdullah habib. Ajaran Tasawuf Syeikh Abdul qadir AlJailani, Bandung: CV Pustaka Setia 2003.

Rekaman serasehan manaqib bersama beliau Nyai Selvi.

Shalahuddin Mahfudh. Pengantar Psikologi Pendidikan, Surabaya: PT. Bina Ilmu, 1990.

Syamsuri Baidlowi. Penuntun Manaqib Syekh Abdul Qadir al-Jailani, Surabaya: Apollo.

Santhut Ahmad Khatib. Daur al-Bait fi tarbiyah al-Tifl al-Muslim, terj. Ibnu Burdah, Menumbuhkan Sikap Sosial, Moral dan Spiritual anak dalam keluarga Muslim, Yokyakarta: Mitra Pustaka, 1998.

Sukardi.Metodelogi Penelitian Pendidikan Kompetensi dan Prakteknya, Jakarta: PT. Bumi Aksara, 2007.

Tim Sekelompok. Putih Jurnal Pengetahuan Tentang Ilmu dan Hikmah, (Surabaya: Ma'had Aly, 2018), 47-48.

Wawancara, Inung Sulistyorini, pada hari sabtu tanggal 23, Maret, 2019.

Wawancara, Ummi Kulsum, pada tanggal, 11 Maret 2019.

Wawancara, Muhammad Bahrowi, pada tanggal, 20 Maret 2019. 